\title{
Literasi Kerajinan Clay untuk Meningkatkan Kreativitas Guru di SDN Jatimekar II Kota Bekasi, Jawa Barat
}

\author{
Maria Ulfa*, Eva Oktaviana, Nur Hasanah \\ STKIP Kusuma Negara \\ *mariaulfa@stkipkusumanegara.ac.id
}

\begin{abstract}
Abstrak
Rendahnya kompetensi guru SD dalam kreativitas pengembangan materi dan media ajar pada masa pandemi Covid-19 menjadi masalah dalam proses pembelajaran daring. Guru SD idealnya harus memiliki kreativitas tinggi agar dapat meningkatkan kemampuan-kemampuan dasar peserta didik. Berdasarkan latar belakang masalah tersebut, salah satu program Pengabdian Kepada Masyarakat (PKM) yang dilakukan dosen sebagai bentuk kepedulian dan kerja sama terhadap peningkatan kompetensi yang dimiliki oleh para guru SD adalah dengan memberikan pengetahuan, pemahaman, dan keterampilan tentang kerajinan clay sebagai materi dan media ajar pada masa pandemi Covid-19 anak SD. Kegiatan ini dibuat dalam bentuk pelatihan dengan tujuan dapat memberikan manfaat agar peserta memiliki kompetensi pembuatan kerajinan clay dengan tepat, dan dapat menerapkan dalam proses pembelajaran daring. STKIP Kusuma Negara Jakarta bekerja sama dengan SDN Jatimekar II Kota Bekasi menyelenggarakan kegiatan PKM yang tepat guna dan sasaran khususnya bagi guru di SDN Jatimekar II Kota Bekasi, Jawa Barat. Hasil pelatihan menunjukkan bahwa minat dan kreativitas peserta sangat tinggi dan dalam waktu singkat memiliki kompetensi dalam pembuatan clay, terbukti peserta mampu menunjukkan hasil dan mampu mengembangkan kreativitas. Evaluasi untuk hasil pelatihan ini bahwa peserta memiliki antusiasme tinggi dan menuntut untuk diadakan pelatihan yang serupa dengan pengembangan variasi bentuk tema clay dari bahan lainnya.
\end{abstract}

Kata Kunci: literasi, kerajinan, clay, sekolah dasar

\section{Clay Crafts Literation to Improve Teacher Creativity at Jatimekar II Elementary School, Bekasi City, West Java}

\begin{abstract}
The low competence of elementary school teachers in the creativity of developing teaching materials and media during the Covid-19 pandemic is a problem in the online learning process. SD teachers should ideally have high creativity in order to improve the basic abilities of students. Based on the background of this problem, one of the community service programs carried out by lecturers as a form of concern and collaboration towards increasing the competence of elementary school teachers is by providing knowledge, understanding, and skills about clay crafts as material and teaching media at during the Covid-19 pandemic elementary school children. This activity is made in the form of training with the aim of being able to provide benefits so that participants have the right competence in making clay crafts, and can apply them in the online learning process. STKIP Kusuma Negara Jakarta in collaboration with Jatimekar II elementary school Bekasi City organizes community service programs activities that are appropriate and targeted especially for teachers at Jatimekar II elementary school Bekasi City, West Java. The results of the training showed that the participants' interest and creativity were very high and in a short time they had competence in making clay, it was proven that the participants were able to show results and were able to develop creativity. The evaluation for the results of this training shows that the participants have high enthusiasm and demand a training similar to the development of various clay themes from other materials.
\end{abstract}

Keywords: literacy, crafts, clay, elementary school

\section{PENDAHULUAN}

Dunia tengah mendapat ujian. Adanya Coronavirus disease (Covid-19) merupakan pandemi yang sangat fenomenal sepanjang kehidupan manusia di era modern saat ini. Dikatakan sangat fenomenal dikarenakan bukan hanya berdasarkan jangkauan penyebaran 
Vol. 2, No. 1, March, 2021, pp. $9-14$

e-ISSN: 2722-2004

Clay Crafts

Literation to

Improve

Teacher

Creativity at

Jatimekar II

Elementary

School, Bekasi

City, West Java

M. Ulfa,

E. Oktaviana,

N. Hasanah

Covid-19 yang sangat luas tetapi orang yang terjangkit pun sangatlah banyak. Semua sektor terkena imbasnya, mulai dari sektor kesehatan, ekonomi, perbankan, pariwisata, budaya, bahkan pendidikan. Tidak ingin larut dalam fenomena Covid19, berdasarkan Surat Edaran Mendikbud Nomor 4 Tahun 2020 tentang Pelaksanaan Pendidikan Dalam Masa Darurat Coronavirus Disease (Covid-19) menandakan semua siswa diwajibkan untuk mengikuti pembelajaran daring. Hal yang sangat baru untuk pendidikan di Indonesia.

Pembelajaran daring dapat dipandang bagai dua sisi mata uang. Satu sisi pembelajaran daring adalah sebagai salah satu solusi dalam mengatasi masalah pendidikan di masa pandemi Covid-19 ini. Akan tetapi di sisi lain pembelajaran daring menjadi ajang siswa untuk menjadi malas dalam belajar. Hal ini dikarenakan siswa banyak yang menganggap remeh pembelajaran daring ini. Guru tidak dapat secara langsung mengawasi siswa dalam belajar dan orang tua yang malas untuk membantu siswa dalam belajar. Akibatnya jalan pintas banyak dilakukan oleh orang tua, yakni dengan mengajarkan tugas-tugas anaknya. Ini adalah salah satu fakta bahwa tingkat kemampuan berliterasi masyarakat Indonesia masih sangatlah rendah.

Salah satu mata pelajaran yang rentan kecurangan seperti tergambar di atas adalah Pendidikan Seni Budaya dan Keterampilan. Mata pelajaran yang seharusnya dapat menstimulus kreativitas siswa seakan tercoreng dalam pembelajaran daring ini. Banyaknya orang tua yang mengerjakan tugas anaknya membuat anak tidak lagi kreatif melainkan menjadi pemalas. Seni Budaya dan Keterampilan di sekolah dasar memberikan kesempatan untuk siswa mengenal tentang berbagai macam jenis-jenis kesenian dan keterampilan. Hal ini tentu saja perlu menjadi perhatian dan guru harus mampu mengembangkan potensi siswa dengan memberikan kesempatan kepada siswa dalam menciptakan karya seni rupa sebagai pernyataan ekspresinya.

Mata pelajaran Pendidikan Seni Budaya dan Keterampilan diberikan di sekolah karena keunikan, kebermaknaan, dan kebermanfaatan terhadap kebutuhan perkembangan peserta didik yang terletak pada pemberian pengalaman dalam bentuk kegiatan berekspresi, berkreasi, dan berapresiasi (Permendiknas Nomor 19 Tahun 2005).

Proses pembelajaran daring seakan mengungkung kreativitas siswa dan membuat siswa menjadi pemalas. Hal tersebut tentunya sangat bertolak belakang dengan tujuan Pendidikan Seni Budaya dan Keterampilan. Metode pengajaran guru yang monoton saat pembelajaran daring, yakni berkutat hanya pada metode penugasan saja menjadi celah siswa untuk menjadi pemalas.

Seperti yang terjadi pada proses pembelajaran di SDN Jatimekar II Kota Bekasi. Salah satu guru menyebutkan bahwa kurangnya kemampuan menguasai materi Pendidikan Seni Budaya dan Keterampilan membuat guru menjadi monoton dalam proses pembelajaran daring. Hanya bermodal buku guru dan buku siswa guru memberikan hanya memberikan tugas terkait materi Pendidikan Seni Budaya dan Keterampilan tanpa memberikan demonstrasi ataupun penjelasan terkait materi yang diajarkan. Metode penugasan dan menagih hasil akhir tugas melalui grup WhatsApp terus berulang dalam setiap proses pembelajaran. Tidak memiliki bekal terkait Pendidikan Seni Budaya dan Keterampilan dan tidak kreatif itulah yang menjadi alasan.

Salah satu materi yang pembelajaran yang dapat dikembangkan dalam Pendidikan Seni Budaya dan Keterampilan adalah seni kriya, yakni clay. Clay adalah bahasa Inggris yang artinya tanah liat. Di Indonesia kata clay menjadi kata 
yang populer dan biasanya identik dengan sebuah kerajinan tangan kerajinan yang unik, karena bahannya dapat dibentuk menjadi berbagai kreasi dengan berbagai fungsi. Kerajinan tangan menggunakan clay sangat mudah dipelajari mulai dari anakanak sampai dewasa (Nirwana, Widyaningsih, dan Sapaile, 2018: 16).

Kerajinan clay dapat dibuat dari berbagai macam bahan, mulai dari polimer, malam, tanah liat, peper, gips, dan tepung (Riska, 2019: 24-28). Dari kelima bahan membuat clay tersebut, tentunya clay tepung adalah bahan termudah untuk diperoleh. Namun, kurangnya pengetahuan dan kreativitas membuat kerajinan clay sering dianggap momok yang menakutkan untuk diajarkan kepada peserta didik.

Diketahui bahwa jumlah guru di SDN Jatimekar II Kota Bekasi adalah 19 guru. Dengan kualifikasi 6 guru lulusan strata 1 PGSD dan 13 guru masih berkualifikasi non strata 1 PGSD. Hal ini membuat guru di SDN Jatimekar II mengalami kesulitan ketika mengajar Pendidikan Seni Budaya dan Keterampilan. Guru wajib mengampu bidang tugasnya sesuai dengan sertifikat yang dimilikinya (Permendikbud Nomor 62 Tahun 2013).

Sejalan dengan Permendikbud tersebut tentunya kualifikasi guru yang tidak sesuai dengan bidang tugas yang diembannya membuat guru menjadi tidak berkompetensi ketika mengajar. Tentunya hal ini terbukti. Oleh sebab itu, sesuai dengan kerja sama yang sudah dibina oleh STKIP Kusuma Negara dengan SDN Jatimekar II Kota Bekasi serta pengajuan permohonan oleh SDN Jatimekar II Kota Bekasi dibuatlah kegiatan pelatihan literasi kerajinan clay untuk meningkatkan kreativitas guru di SDN Jatimekar II Kota Bekasi.

\section{METODE PELAKSANAAN}

Pelatihan literasi kerajinan clay untuk meningkatkan kreativitas guru di SDN Jatimekar II Kota Bekasi dilaksanakan pada Sabtu, 19 Desember 2020. Pelaksanaan PKM oleh tim dosen PGSD, STKIP Kusuma Negara dilaksanakan secara langsung di SDN Jatimekar II Kota Bekasi dengan menerapkan protokol kesehatan sesuai prosedur dari pemerintah.

Subjek kegiatan PKM ini adalah sebanyak 15 guru SDN Jatimekar II Kota Bekasi. Adapun instrumen yang digunakan oleh tim PKM PGSD, STKIP Kusuma Negara adalah peralatan untuk membuat kerajinan. Instrumen pelatihan disediakan oleh pihak SDN Jatimekar II Kota Bekasi sesuai dengan koordinasi saat observasi yang dilaksanakan sebelum kegiatan PKM dilaksanakan.

SDN Jatimekar II Kota Bekasi merupakan mitra STKIP Kusuma Negara yang tercantum dalam perjanjian kerja sama Nomor: 310/STKIP-KN/VIII/2018 Tentang Penyelenggaraan Pendidikan, Penelitian, dan Pengabdian Kepada Masyarakat. Pada tanggal 11 Desember 2020 pihak SDN Jatimekar II Kota Bekasi mengajukan permohonan untuk pengiriman narasumber pelatihan kepada Ketua STKIP Kusuma Negara.

Tanggal 16 Desember 2020, Ketua STKIP Kusuma Negara memberikan tugas kepada 5 dosen PGSD untuk melaksanakan PKM di SDN Jatimekar II Kota Bekasi. Selanjutnya, pihak dosen PGSD dan SDN Jatimekar II Kota Bekasi melaksanakan koordinasi dan melaksanakan observasi tentang kebutuhan dari SDN Jatimekar II Kota Bekasi terkait judul pelatihan, yakni Literasi Kerajinan Clay untuk Meningkatkan Kreativitas Guru di SDN Jatimekar II Kota Bekasi. Kemudian pihak dosen membagi tugas untuk penyampaian materi di pelatihan tersebut. Pihak SDN Jatimekar II Kota Bekasi selaku pemohon yang menyiapkan segala peralatan yang digunakan untuk PKM ini.
KANGMAS is a journal published by Neolectura, issued three times in one year. KANGMAS is a scientific publication media in the form of conceptual paper and field research related to social service work. It is hoped that KANGMAS can become a media for academics and researchers to publish their social service work and become a reference source for the development of social and humanity.

Our focus: Social Service

Our Scope:

Humanities,

Education,

Management, History,

Economics,

Linguistics,

Literature,

Religion,

Politics,

Sociology, Anthropology, and other social service works. 
Vol. 2, No. 1, March, 2021, pp. 9-14

e-ISSN: 2722-2004

Clay Crafts

Literation to

Improve

Teacher

Creativity at

Jatimekar II

Elementary

School, Bekasi

City, West Java

M. Ulfa,

E. Oktaviana,

N. Hasanah

\section{HASIL DAN PEMBAHASAN}

SDN Jatimekar II Kota Bekasi terletak di Jalan Benda RT 01 RW 06 Kp. Pamahan Kel. Jatimekar, Kec. Jatiasih, Kota Bekasi, Provinsi Jawa Barat. SDN Jatimekar II didirikan pada 1976 dan bernomor NPSN 20222800. Luas tanah dan bangunan SDN Jatimekar II Kota Bekasi $1975 \mathrm{~m}^{2}$. Saat ini SDN Jatimekar II Kota Bekasi terakreditasi A BAN-S.

Saat ini SDN Jatimekar II Kota Bekasi memiliki 19 guru. Terdiri dari 6 PNS dan 13 GTK, serta 6 guru lulusan strata 1 PGSD dan 13 guru masih berkualifikasi non-strata 1 PGSD. Salah satu kelemahan dalam proses pembelajaran langsung atau daring seperti saat ini adalah kualifikasi guru yang tidak sesuai. Perbandingan guru berkualifikasi strata 1 PGSD dengan non-PGSD tidak sampai setengah jumlah guru di SDN Jatimekar II Kota Bekasi.

Ketidaklinieran guru-guru di SDN Jatimekar II Kota Bekasi menjadi penghambat dalam proses pembelajaran. Salah satu kompetensi yang harus dimiliki guru adalah kompetensi profesional. Di mana guru haruslah menguasai bidang keilmuannya. Begitu pula dengan guru SD yang harus menguasai ilmu ke-SD-an. yang tentunya secara akademik dipelajari hanya pada jurusan PGSD saja.

Kepala Sekolah SDN Jatimekar II Kota Bekasi mengharapkan guru-guru yang non-linear memiliki kemampuan dan kompetensi yang sebanding dengan guru dengan kualifikasi strata 1 PGSD. Guru-guru SDN Jatimekar II Kota Bekasi sudah sering mengikuti BIMTEK yang diberikan oleh dinas pendidikan dan instansi lainnya. Namun dengan adanya pandemi Covid-19 ini kegiatan tersebut menjadi terbatas.

Pada 16 Desember 2020 pihak STKIP Kusuma Negara memberikan tugas kepada 5 dosen PGSD untuk melaksanakan PKM di SDN Jatimekar II Kota Bekasi. Tim PKM PGSD, STKIP Kusuma Negara langsung melaksanakan rapat koordinasi terkait dengan PKM yang akan dilaksanakan. Selaku ketua PKM, Maria Ulfa, M.Pd. meminta Chrisnaji Banindra Yudha, M.Pd. untuk mengoordinasikan terkait kebutuhan SDN Jatimekar II Kota Bekasi. Setelah diketahui kebutuhan yang diperlukan oleh mitra PKM, Ketua PKM memberikan materi PKM kepada Eva Oktaviana, M.Pd., Nur Hasanah, M. Hum, dan Risky Dwiprabowo, M.Pd. sesuai dengan kualifikasi yang dimiliki lalu menyusun materi-materi yang akan diberikan kepada peserta pelatihan.

Pelaksanaan PKM dilakukan dengan susunan kegiatan sebagai berikut:

1. Pembukaan oleh Kepala Sekolah dan Ketua Tim PKM PGSD, STKIP Kusuma Negara

2. Pemaparan materi Pentingnya Kreativitas untuk Guru

3. Ice breaking

4. Pemaparan materi Pendidikan Seni Budaya dan Keterampilan di SD Saat Pembelajaran Daring (Kerajinan Clay Tepung)

5. Ice Breaking

6. Praktik Pembuatan

7. Penutup

Kegiatan PKM Literasi Kerajinan Clay untuk Meningkatkan Kreativitas Guru di SDN Jatimekar II Kota Bekasi diikuti oleh 15 guru. Dari kegiatan pembuka sampai dengan kegiatan penutup diikuti oleh seluruh peserta dengan antusias yang tinggi dapat dilihat dari banyak guru yang bertanya saat proses pelatihan. Kegiatan ini bukan hanya memberikan materi terkait kreativitas dan Pendidikan Seni Budaya dan Keterampilan di SD tetapi juga memberikan kesempatan kepada peserta untuk 
KANGMAS: Karya Ilmiah Pengabdian Masyarakat, Vol. 2 No. 1, March 2021 - 13

http://journal.neolectura.com/index.php/kangmas

langsung membuat prakarya clay dari barang-barang yang sangat mudah untuk ditemui dan dijangkau.

Berikut ini adalah alat dan bahan yang digunakan untuk membuat prakarya clay:

1. Baskom

2. Sendok

3. Kuas

4. Tepung beras

5. Tepung terigu
6. Tepung tapioka

7. Tepung meizena

8. Baby oil

9. Lem Fox

10. Cat poster color

\section{Natrium}

benzoate

Pemaparan materi dan praktik membuat prakarya clay dapat dilihat pada fotofoto pelatihan berikut ini:

1. Langkah pertama siapkan alat dan bahannya.

2. Langkah kedua masukan tepung beras dan tepung maizena masingmasing 5 sendok.

3. Langkah ketiga masukan 5 sendok tepung kanji.

4. Langkah keempat masukan 5 sendok tepung beras.

5. Kemudian masukan 1 sendok maizena, lem Fox, dan baby oil secukupnya.

6. Jika semua bahan sudah masuk, aduk hingga rata dan menjadi adonan.

7. Adonan bagi menjadi lima bagian atau sesuai selera.

8. Berikan warna yang berbeda di setiap bagian yang sudah disiapkan.

9. Dari adonan yang sudah diberi warna kita bentuk menjadi media apa saja sesuai keinginan.
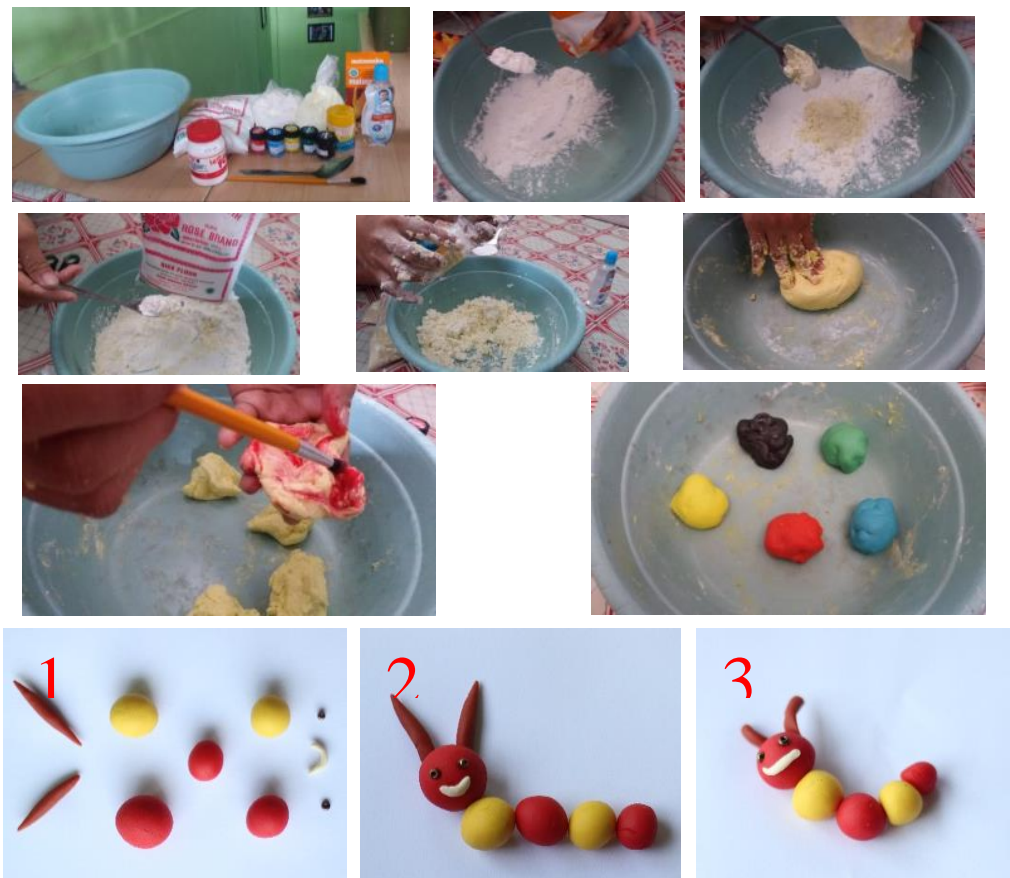

Gambar 1. Langkah-langkah Membuat Kerajinan Clay Art

Materi dan praktik membuat prakarya kerajinan menambah rasa percaya diri peserta bahwa Pendidikan Seni Budaya dan Keterampilan di SD adalah pelajaran yang mudah. Kreativitas seorang guru sangat diperlukan dalam pelaksanaan pembelajaran, khususnya pada pelajaran Pendidikan Seni Budaya dan Keterampilan. Tidak harus mahal dan dengan metode yang rumit untuk dalam melaksanakan pembelajaran Pendidikan 
Vol. 2, No. 1, March, 2021, pp. 9-14

e-ISSN: 2722-2004

Clay Crafts

Literation to

Improve

Teacher

Creativity at

Jatimekar II

Elementary

School, Bekasi

City, West

Java

M. Ulfa,

E. Oktaviana,

N. Hasanah

Seni Budaya dan Keterampilan di SD. Tetapi dengan niat dan usaha akan memupuk kreativitas guru dalam melaksanakan proses pembelajaran. Berikut ini adalah hasil karya atau kerajinan clay art peserta pelatihan.

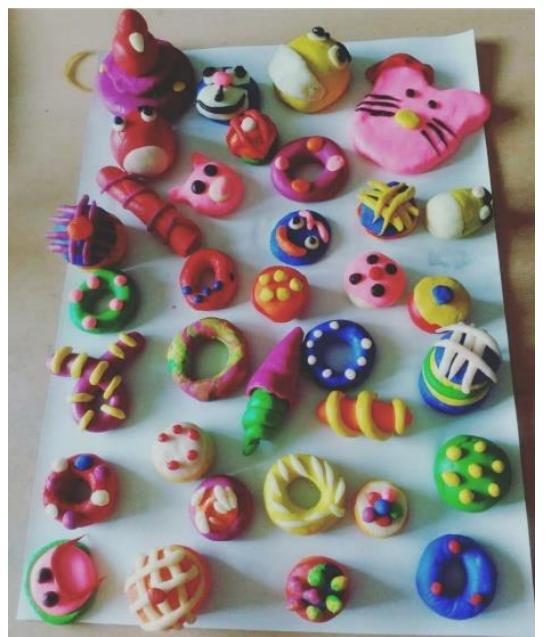

Gambar 2. Hasil Kerajinan Clay Art Peserta Pelatihan

\section{SIMPULAN}

Berdasarkan PKM Literasi Kerajinan Clay untuk Meningkatkan Kreativitas Guru di SDN Jatimekar II Kota Bekasi yang dilaksanakan oleh Tim Dosen PGSD, STKIP Kusuma Negara didapatkan hasil pemahaman terkait Pendidikan Seni Budaya dan Keterampilan di SD saat pembelajaran daring. Guru yang baik adalah guru yang mampu menciptakan pembelajaran yang menyenangkan dan mampu menggali potensi yang ada pada diri siswa. Untuk itu, guru yang kreatif akan menciptakan siswa yang kreatif juga.

Pelaksanaan kegiatan ini memberikan pengalaman yang nyata kepada peserta tentang kreativitas membuat karya seni dari clay berbahan dasar tepung. Pelaksana juga berharap kegiatan pelatihan seperti ini dapat terlaksana kembali dengan jumlah peserta yang lebih banyak.

\section{DAFTAR PUSTAKA}

Nirwana, O. W. dan Sapaile, N. (2018). Pelatihan kreativitas clay bagi guru PAUD Kecamatan Tambora, Jakarta Pusat. Sarwahita: Jurnal Pengabdian Kepada Masyarakat 15(1), 13-21. https://doi.org/10.21009/sarwahita.151.02

Peraturan Pemerintah Republik Indonesia 2005 Tentang Rencana Strategis Pendidikan Nasional.

Permendikbud Nomor 62 Tahun 2013 Tentang Sertifikasi Guru Dalam Jabatan Dalam Rangka Penataan Dan Pemerataan Guru.

Riska. (2019). Proses pembuatan kerajinan tangan dengan bahan polymer clay buatan pada siswa kelas IX MTs PP Kelautan Perak Pulau Sabutung Kabupaten Pangkep. Skripsi. https://digilibadmin.unismuh.ac.id/upload/8698Full_Text.pdf 